УДК 615.32: $547.9+543.544$

\title{
НОВЫЕ ПОДХОДЫ К СТАНДАРТИЗАЦИИ ЦВЕТКОВ БОЯРЫШНИКА
}

\author{
() А.В. Куркина \\ Самарский государственный медицинский университет, ул. Чапаевская, 89, \\ Самара, 443099 (Россия), e-mail: Annushkae@yandex.ru
}

\begin{abstract}
Разработана методика количественного определения суммы флавоноидов в цветках боярышника кроваво-красного (Crataegus sanguinea Pall.) с использованием метода дифференциальной спектрофотометрии (аналитическая длина волны 412 нм) и ГСО гиперозида. С использованием разработанной методики проанализирован ряд образцов сырья и показано, что содержание флавоноидов в цветках боярышника варьирует в пределах от 1,41 до 1,84\% (в пересчете на гиперозид). Результаты статистической обработки проведенных опытов свидетельствуют о том, что ошибка единичного определения суммы флавоноидов в цветках боярышника с доверительной вероятностью $95 \%$ составляет $\pm 4,46 \%$.

Ключевые слова: боярышник кроваво-красный, Crataegus sanguinea Pall., цветки, флавоноиды, гиперозид, спектрофотометрия.
\end{abstract}

\section{Введение}

Цветки и плоды боярышника кроваво-красного (Crataegus sanguinea Pall.) и других фармакопейных видов широко применяется в медицине в качестве кардиотонических и гипохолестеринемических средств при лечении различных сердечно-сосудистых заболеваний [1-3]. Ведущей группой биологически активных соединений сырья данного растения являются флавоноиды, хотя и другие вещества, например, сапонины, вносят вклад в фармакологический эффект [4, 5]. Стандартизацию цветков боярышника осуществляют по содержанию гиперозида (не менее 0,5\%) [6], однако, на наш взгляд, методика количественного определения содержания гиперозида в сырье данного растения крайне сложна и многостадийна, что неизбежно может приводить к потере анализируемого флавоноида и, следовательно, к занижению результатов анализа. Кроме того, в фармакопейной методике многостадийная пробоподготовка предусмотрена и для Государственного стандартного образца (ГСО) гиперозида, что тоже не только усложняет методику, но и может сказываться на точности анализа. В соответствии с этим актуальными являются исследования по совершенствованию химической стандартизации цветков боярышника.

На наш взгляд, объективным критерием качества цветков боярышника может быть числовой показатель «содержание суммы флавоноидов», как это имеет место в ряде других растений, содержащих флавоноиды [4-8].

Цель настоящих исследований - разработка методики количественного определения суммы флавоноидов в цветках боярышника.

\section{Экспериментальная часть и обсуждение результатов}

В качестве объекта исследования служили образцы цветков боярышника кроваво-красного (Crataegus sanguinea Pall.), собранные в 2010-2012 гг. в Самарской области (пос. Просвет, окр. Самары, Ботанический сад Самарского государственного университета), а также промышленный образец плодов боярышника (ОАО «Красногорсклексредства», 2012 г., серия 10112). С целью разработки методики нами были определены оптимальные условия экстракции цветков боярышника: экстрагент - 70\% этанол; соотношение «сырье - экстрагент» - $1: 30$; время экстракции н на водяной бане при температуре $85-90{ }^{\circ} \mathrm{C}$ в течение 60 мин (табл. 1). При этом следует обратить внимание, что в случае 95\% этилового спирта, применяе-

Куркина Анна Владимировна - ассистент кафедры фармакогнозии с ботаникой и основами фитотерапии, тел. (846) 260-33-59, e-mail: Annushkae@yandex.ru мого в фармакопейное методике в качестве экстрагента [6], содержание суммы флавоноидов почти в 3 раза ниже по сравнению с оптимальным вариантом 
(табл. 1). Этот факт можно объяснить плохой растворимостью гиперозида в 95\% этиловом спирте. Именно по этой причине для приготовления раствора ГСО гиперозида нами вместо 95\% этилового спирта рекомендован в качестве растворителя $70 \%$ этиловый спирт (см. Примечание в методике).

В ходе разработки методики количественного определения суммы флавоноидов в цветках боярышника изучены УФ-спектры растворов водно-спиртовых извлечений из данного сырья. Регистрацию спектров проводили с помощью спектрофотометра «Specord 40» (Analytik Jena).

При разработке методики количественного определения суммы флавоноидов использовали реакцию комплексообразования с раствором алюминия хлорида для исключения вклада в значение оптической плотности других групп соединений $[9,10]$, в том числе характерных для данного растения гидроксикоричных кислот, имеющих, как правило, основной максимум поглощения в области 280-330 нм [11]. В условиях комплексообразования наблюдается батохромный сдвиг длинноволновой полосы флавоноидов, который обнаруживается в УФ-спектре в виде максимума поглощения в области 400-412 нм, как в случае раствора извлечения из цветков, так и в электронном спектре гиперозида (рис. 1), что находит подтверждение в условиях дифференциальной спектрофотометрии (рис. 2).

Изучение УФ-спектров ГСО гиперозида показало, что раствор данного стандарта в присутствии хлорида алюминия имеет максимум поглощения при 412 нм, в том числе в дифференциальном варианте (рис. 3 и 4).

Таблица 1. Зависимость полноты извлечения суммы флавоноидов из цветков боярышника от условий экстракции

\begin{tabular}{c|c|c|c}
\hline $\begin{array}{c}\text { Концентрация } \\
\text { этанола, } \%\end{array}$ & $\begin{array}{c}\text { Соотношение } \\
\text { сырье : экстрагент }\end{array}$ & $\begin{array}{c}\text { Время экстракции, } \\
\text { мин }\end{array}$ & $\begin{array}{c}\text { Содержание суммы флавоноидов в пересчете } \\
\text { на гиперозид и абсолютно сухое сырье (в \%) }\end{array}$ \\
\hline 40 & $1: 30$ & 60 & $0,73 \pm 0,02$ \\
50 & $1: 30$ & 60 & $0,84 \pm 0,02$ \\
60 & $1: 30$ & 60 & $1,44 \pm 0,03$ \\
70 & $1: 30$ & 60 & $1,50 \pm 0,03$ \\
80 & $1: 30$ & 60 & $1,45 \pm 0,02$ \\
95 & $1: 30$ & 60 & $0,57 \pm 0,01$ \\
70 & $1: 30$ & 30 & $1,41 \pm 0,02$ \\
70 & $1: 30$ & 45 & $1,48 \pm 0,02$ \\
70 & $1: 30$ & 60 & $1,50 \pm 0,03$ \\
70 & $1: 30$ & 120 & $1,47 \pm 0,02$ \\
70 & $1: 30$ & 60 & $1,41 \pm 0,02$ \\
70 & $1: 20$ & 60 & $1,40 \pm 0,02$ \\
70 & $1: 50$ & & $1,51 \pm 0,03$ \\
\hline
\end{tabular}

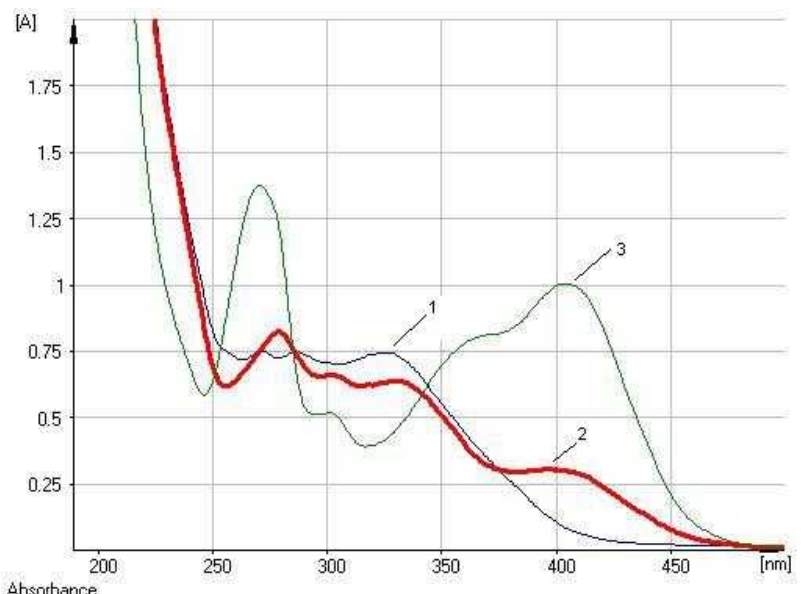

Рис. 1. УФ-спектры растворов водно-спиртового извлечения из цветков боярышника кровавокрасного: 1 - раствор извлечения; 2 - раствор извлечения с добавлением алюминия хлорида; 3 - раствор гиперозида с добавлением хлорида алюминия

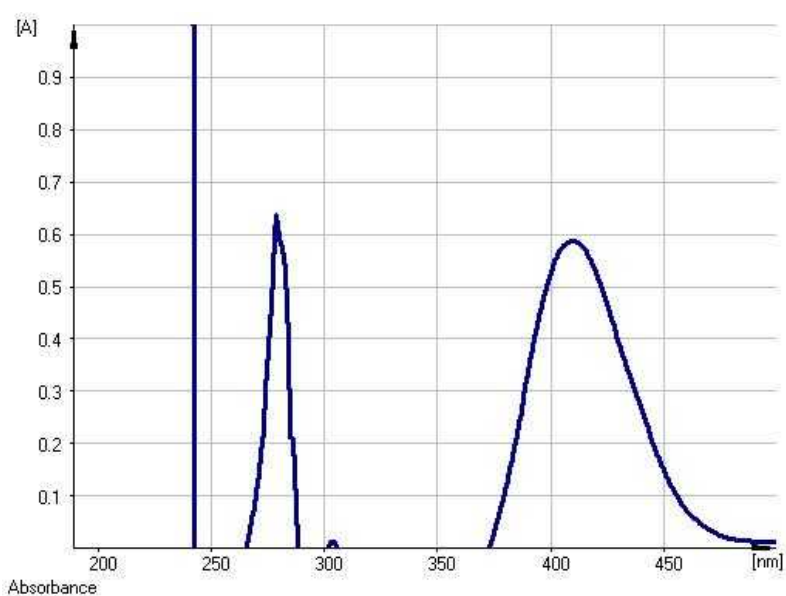

Рис. 2. УФ-спектр раствора водно-спиртового извлечения из цветков боярышника кровавокрасного (дифференциальный спектр) 


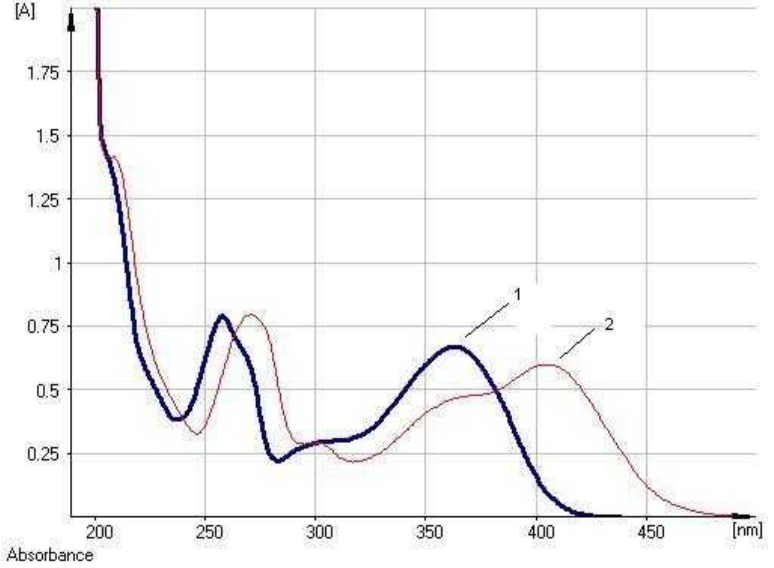

Рис. 3. УФ-спектр спиртового раствора ГСО гиперозида: 1 - раствор ГСО гиперозида; 2 - раствор ГСО гиперозида с добавлением хлорида алюминия

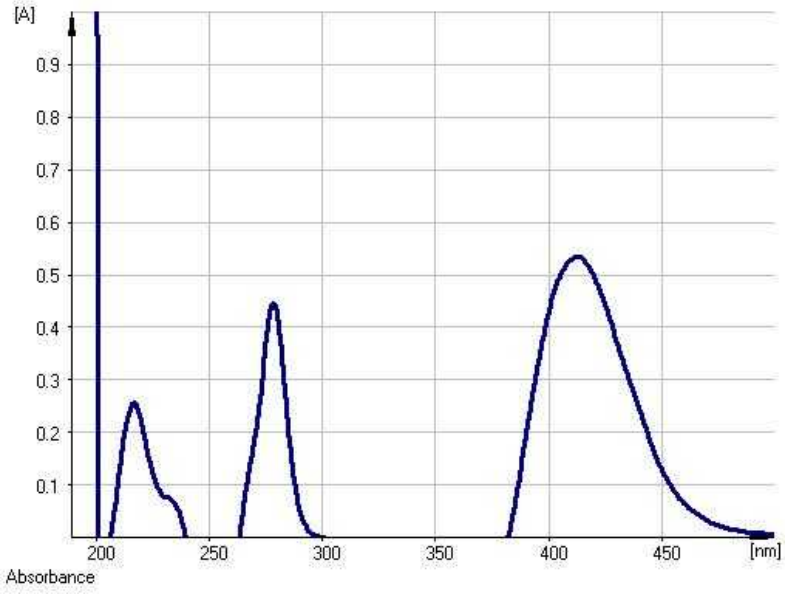

Рис. 4. УФ-спектр раствора ГСО гиперозида (дифференциальный спектр)

Следовательно, гиперозид может быть использован в методике анализа в качестве ГСО. Кроме того, сравнение УФ-спектров извлечений из цветков и плодов боярышника кроваво-красного показало, что их спектральные характеристики резко отличаются (рис. 5). Так, для плодов данного растения характерен интенсивный максимум поглощения при длине волны $285 \pm 2$ нм, тогда как в случае цветков наблюдаются три максимума поглощения, обусловленные флавоноидами и гидроксикоричными кислотами (рис. 5). Это может быть успешно использовано для диагностики данных видов сырья, принимая во внимание то обстоятельство, что в разделе «Качественные реакции» и в плодах, и в цветках боярышника предусмотрено обнаружение методом тонкослойной хроматографии гиперозида [5], являющегося в данном случае общим, а не отличительным признаком.

Методика количественного определения суммы флавоноидов в цветках боярышника. Аналитическую пробу сырья измельчают до размера частиц, проходящих сквозь сито с отверстиями диаметром 1 мм. Около 1 г измельченного сырья (точная навеска) помещают в колбу со шлифом вместимостью 50 мл, прибавляют 30 мл 70\% этилового спирта. Колбу закрывают пробкой и взвешивают на аналитических весах с точностью до $\pm 0,0001$ г. Колбу присоединяют к обратному холодильнику и нагревают на кипящей водяной бане (умеренное кипение) в течение 60 мин. Затем колбу с извлечением охлаждают в течение 30 мин, закрывают той же пробкой, снова взвешивают и восполняют недостающий экстрагент до первоначальной массы. Полученное извлечение фильтруют через фильтр (красная полоса). Испытуемый раствор готовят следующим образом: 1 мл полученного извлечения помещают в мерную колбу вместимостью 25 мл, прибавляют 2 мл 3\% спиртового раствора алюминия хлорида и доводят объем раствора до метки 95\% этиловым спиртом (испытуемый раствор А). В качестве раствора сравнения используют раствор, приготовленный при тех же условиях, но без добавления алюминия хлорида (раствор сравнения А). Измерение оптической плотности проводят на спектрофотометре при длине волны 412 нм. Параллельно измеряют оптическую плотность раствора ГСО гиперозида при длине волны 412 нм, приготовленного по аналогии с испытуемым раствором (см. примечание).

Примечание. Приготовление раствора гиперозида-стандартного образиа. Около 0,02 г (точная навеска) гиперозида помещают в мерную колбу вместимостью 50 мл, растворяют в 30 мл $70 \%$ этилового спирта при нагревании на водяной бане. После охлаждения содержимого колбы до комнатной температуры доводят объем раствора 70\% этиловым спиртом до метки (раствор А гиперозида). 1 мл раствора А гиперозида помещают в мерную колбу на 25 мл, прибавляют 1 мл 3\% спиртового раствора хлорида алюминия и доводят объем раствора 95\% этиловым спиртом до метки (испытуемый раствор Б гиперозида). В качестве раствора сравнения используют раствор, который готовят следующим образом: 1 мл раствора А гиперозида помещают в мерную колбу на 25 мл и доводят объем раствора до метки 95\% этиловым спиртом (раствор сравнения Б гиперозида). 


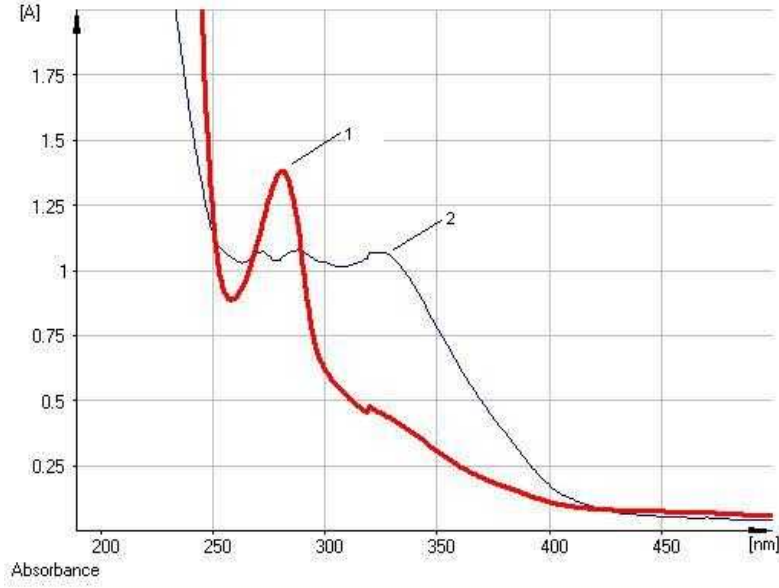

Рис. 5. УФ-спектр раствора водно-спиртового извлечения из плодов (1) и цветков (2) боярышника кроваво-красного

Содержание суммы флавоноидов в пересчете на гиперозид и абсолютно сухое сырье в процентах $(X)$ вычисляют по формуле:

$$
X=\frac{D \cdot m_{0} \cdot 30 \cdot 1 \cdot 25 \cdot 100 \cdot 100}{D_{0} \cdot m \cdot 50 \cdot 1 \cdot 25 \cdot(100-W)}
$$

где $D$ - оптическая плотность испытуемого раствора; $D_{o}$ - оптическая плотность раствора ГСО гиперозида; $m$ - масса сырья, г; $m_{o}$ - масса ГСО гиперозида, г; $W$ - потеря в массе при высушивании в процентах.

Целесообразным также представляется расчет содержания суммы флавоноидов с использованием значения удельного показателя поглощения гиперозида (330). В этом случае расчет содержания суммы флавоноидов в сырье осуществляют по упрощенной формуле:

$$
X=\frac{D \cdot 30 \cdot 25 \cdot 100}{330 \cdot m \cdot 1 \cdot(100-W)},
$$

где $D$ - оптическая плотность испытуемого раствора; 330 - удельный показатель поглощения комплекса гиперозида с хлоридом алюминия при 412 нм; $m$ - масса сырья, г; $W$ - потеря в массе при высушивании в процентах.

С использованием разработанной методики проанализирован ряд образцов цветков боярышника и показано (табл. 2), что содержание суммы флавоноидов в образцах сырья варьирует в пределах от 1,41 до $1,84 \%$ (в пересчете на гиперозид). Это позволяет предварительно рекомендовать в качестве числового показателя «содержание суммы флавоноидов» значение «не менее 1,4\%» (взамен «содержание гиперозида не менее $0,5 \% »)$, хотя исследования по уточнению данного показателя должны быть продолжены (с учетом срока годности).

Метрологические характеристики методики количественного определения флавоноидов в цветках боярышника представлены в таблице 3 .

Таблица 2. Содержание суммы флавоноидов в различных образцах цветков боярышника

\begin{tabular}{l|c}
\hline \multicolumn{1}{c|}{ Характеристика образца сырья } & $\begin{array}{c}\text { Содержание суммы флавоноидов } \\
\text { в пересчете на гиперозид и а.с.с., \% }\end{array}$ \\
\hline Самарская область (пос. Просвет), 23.05.2011 г. & $1,41+0,02$ \\
Самарская область (окр. г. Самары), 04.05.2012 г. & $1,84+0,04$ \\
Ботанический сад Самарского государственного университета, 20.05.2011 г. & $1,50+0,03$ \\
Ботанический сад Самарского государственного университета, 05.05.2012 г. & $1,65+0,02$ \\
\hline
\end{tabular}

Таблица 3. Метрологические характеристики методики количественного определения содержания суммы флавоноидов в цветках боярышника

\begin{tabular}{c|c|c|c|c|c|cc}
\hline $\mathrm{f}$ & $\bar{X}$ & $S$ & $P, \%$ & $t(\mathrm{P}, \mathrm{f})$ & $\Delta X$ & $E, \%$ \\
\hline 10 & 1,50 & 0,0300 & 95 & 2,23 & $\pm 0,067$ & $\pm 4,46$ \\
\hline
\end{tabular}


Результаты статистической обработки проведенных опытов свидетельствуют о том, что ошибка единичного определения суммы флавоноидов в цветках боярышника с доверительной вероятностью $95 \%$ составляет $\pm 4,46 \%$.

Опыты с добавками РСО гиперозида к навеске сырья показали, что ошибка анализа находится в пределах ошибки единичного определения, что свидетельствует об отсутствии систематической ошибки разработанной методики (опыты с добавками) (табл. 4).

Таблица 4. Содержание суммы флавоноидов в цветках боярышника в зависимости от добавления гиперозида

\begin{tabular}{c|c|c|c|c|c}
\hline $\begin{array}{c}\text { Исходное содер- } \\
\text { жание суммы фла- } \\
\text { воноидов, мг/г }\end{array}$ & $\begin{array}{c}\text { Добавление } \\
\text { гиперозида } \\
\text { (в сырье), }\end{array}$ & Сг $/ \Gamma$ & расчержание суммы флавоноидов, мг/г & \multicolumn{2}{|c}{ Ошибка } \\
\cline { 4 - 6 } & 4,0 & 19,0 & 18,5 & $-0,5$ & $-2,63$ \\
15,0 & 8,0 & 23,0 & 23,6 & $+0,4$ & $+1,74$ \\
15,0 & 12,0 & 27,0 & 27,6 & $+0,6$ & $+2,20$ \\
\hline
\end{tabular}

\section{Заключение}

Таким образом, разработана методика количественного определения суммы флавоноидов в цветках боярышника с использованием метода дифференциальной спектрофотометрии (аналитическая длина волны 412 нм). Обоснованно использовать в разработанной методике гиперозид в качестве ГСО. Содержание суммы флавоноидов в образцах цветков боярышника варьирует в пределах от 1,41 до 1,84\% (в пересчете на гиперозид). Спектральные характеристики электронного спектра могут быть использованы также для целей идентификации сырья и препаратов данного растения. На наш взгляд, внедрение данной методики, отвечающей параметрам валидации, позволит объективно оценивать качество цветков боярышника.

\section{Выводы}

1. Разработана методика количественного определения суммы флавоноидов в цветках боярышника кроваво-красного (Crataegus sanguinea Pall.) с использованием метода дифференциальной спектрофотометрии (аналитическая длина волны 412 нм) и ГСО гиперозида.

2. С использованием разработанной методики проанализирован ряд образцов цветков боярышника и показано, что содержание флавоноидов в сырье данного растения варьирует в пределах от 1,41 до 1,84\% (в пересчете на гиперозид). Результаты статистической обработки проведенных опытов свидетельствуют о том, что ошибка единичного определения суммы флавоноидов в цветках боярышника с доверительной вероятностью $95 \%$ составляет $\pm 4,46 \%$.

3. Спектральные характеристики электронного спектра раствора извлечений из цветков и плодов боярышника могут быть использованы для дифференциальной диагностики данных видов сырья и лекарственных препаратов на их основе (настойка, экстракт и др.).

\section{Список литературы}

1. Государственный реестр лекарственных средств. Официальное издание. М., 2008. Т. 1, 2.

2. Куркин В.А. Основы фитотерапии. Самара, 2009. 963 с.

3. Растительные ресурсы СССР: цветковые растения, их химический состав, использование; Семейство $H y$ drangeaceae - Haloragaceae. СПб., 1987. 326 с.

4. Куркин В.А. Фармакогнозия. 2-е изд. Самара, 2007. 1239 с.

5. Муравьева Д.А., Самылина И.А., Яковлев Г.П. Фармакогнозия. М., 2007. 656 с.

6. Государственная фармакопея СССР. Вып. 2: Общие методы анализа. Лекарственное растительное сырье. М., 1989. $400 \mathrm{c}$.

7. Корулькин Д.Ю., Абилов Ж.А., Музычкина Р.А., Толстиков Г.А. Природные флавоноиды. Новосибирск, 2007. 232 c.

8. Wagner H. Pharmazeutische Biologie. Drogen und ihre Inhaltsstoffe. Stuttgart; New York, 1993. $522 \mathrm{s.}$

9. The Flavonoids / Ed. by J.B. Harborne, T.J. Mabry, H. Mabry. London; New York, 1975. 1204 p.

10. Mabry T.J., Markham K.R., Thomas M.B. The Systematic Identification of Flavonoids. Berlin; Heidelberg; New York, 1970.354 p. 
11. Куркин В.А., Авдеева Е.В. Проблемы стандартизации растительного сырья и препаратов, содержащих фенилпропаноиды // Фармация. 2009. Т. 57, №1. С. 51-54.

Поступило в редакииию 7 июля 2012 2.

\section{Kurkina A.V. THE NEW APPROACHES TO THE STANDARDIZATION OF GRATAEGUS FLOWERS}

Samara State Medical University, ul. Chapaevskaia, 89, Samara, 443099 (Russia), e-mail: Annushkae@yandex.ru

The method of the quantitative estimation of the total flavonoids in the flowers of Crataegus sanguinea Pall. by using of the differential spectrophotometry (analytical wave-length at $412 \mathrm{~nm}$ ) and of state standard sample of hyperoside was developed. The contents of the total flavonoids in the Crataegus sanguinea flowers are varied from 1,41 to 1,84\% (calculated on the hyperoside). The relative degree of the determination of the total flavonoids in developed method with confidence probability 0,95 is no more than $\pm 4,46 \%$.

Keywords: Crataegus sanguinea Pall., flowers, flavonoids, hyperoside, spectrophotometry.

\section{References}

1. Gosudarstvennyi reestr lekarstvennykh sredstv. Ofitsial'noe izdanie. [State register of medicines. Official edition]. Moscow, 2008, vol. 1, 2. (in Russ.).

2. Kurkin V.A. Osnovy fitoterapii. [Fundamentals of phytotherapy]. Samara, 2009, 963 p. (in Russ.).

3. Rastitel'nye resursy SSSR: Tsvetkovye rasteniia, ikh khimicheskii sostav, ispol'zovanie; Semeistvo Hydrangeaceae Haloragaceae. [Plant Resources of the USSR: Flowering plants, their chemical composition, the use, family Hydrangeaceae - Haloragaceae]. Saint Petersburg, 1987, 326 p. (in Russ.).

4. Kurkin V.A. Farmakognoziia. 2-e izd. [Pharmacognosy. 2nd ed.]. Samara, 2007, 1239 p. (in Russ.).

5. Murav'eva D.A., Samylina I.A., Iakovlev G.P. Farmakognoziia. [Pharmacognosy]. Moscow, 2007, 656 p. (in Russ.).

6. Gosudarstvennaia farmakopeia SSSR: Vyp. 2. Obshchie metody analiza. Lekarstvennoe rastitel'noe syr'e. [State Pharmacopoeia of the USSR, Vol. 2. Common methods of analysis. Herbal drugs]. Moscow, 1989, 400 p. (in Russ.).

7. Korul'kin D.Iu., Abilov Zh.A., Muzychkina R.A., Tolstikov G.A. Prirodnye flavonoidy. [Natural flavonoids.]. Novosibirsk, 2007, 232 p. (in Russ.).

8. Wagner H. Pharmazeutische Biologie. Drogen und ihre Inhaltsstoffe. Stuttgart; New York, 1993, $522 \mathrm{s.}$

9. The Flavonoids. Ed. by J.B. Harborne, T.J. Mabry, H. Mabry. London; New York, 1975, 1204 p.

10. Mabry T.J., Markham K.R., Thomas M.B. The Systematic Identification of Flavonoids. Berlin; Heidelberg; New York, 1970, $354 \mathrm{p}$.

11. Kurkin V.A., Avdeeva E.V. Farmatsiia, 2009, vol. 57, no. 1, pp. 51-54. (in Russ.). 